\title{
Strategies for improving the repair of focal cartilage defects
}

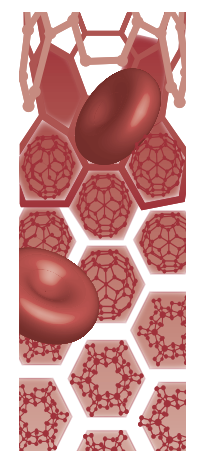

Articular cartilage, together with skin, was predicted to be one of the first tissues to be successfully engineered. However cartilage repair remains nowadays still elusive, as we are still not able to overcome the hurdles of creating biomaterials corresponding to the native properties of the tissue, and which operate in joints environment that is not favorable for regeneration. In this review, we give an overview of the outcome of current cartilage treatment techniques. Furthermore we present current research strategies for improving cartilage tissue engineering.

\section{Keywords: $\mathrm{ACl} \bullet \mathrm{AMIC} \bullet$ cartilage repair $\bullet$ hydrogel $\bullet \mathrm{MACl} \bullet$ microfracture $\bullet$ repair} - scaffold

Articular cartilage focal lesion following a recreational activity such as football is a very common event that repeats thousands of times every week-end around the world. As illustration, the analysis of 25,124 knee arthroscopies performed from 1989 to 2004 in two Polish centers has revealed cartilage lesions in $60 \%$ of the patients [1], with more than $40 \%$ that were due to football injuries (Figure 1). In a review of 993 arthroscopies, localized cartilage defects were found in $20 \%$ of the knees in patients with a mean age of 35 years, showing thus a significant incidence in young adult population [2]. It has also been reported that $5 \%$ of 31,516 knee arthroscopies diagnosed full-thickness cartilage lesions for patients under 40 years of age [3]. It is also notable to mention that a non-negligible percentage of cartilage lesions is asymptomatic, as it has been diagnosed for $5-10 \%$ of NBA players [4].

Despite diverse approaches, nowadays there is no treatment able to restore hyalinelike cartilage with native tissue characteristics (Figure 2), which consists of an extracellular matrix (ECM) composed of water (70 to $80 \%$ ), collagen (50 to $75 \%$ of dry weight) and glycosaminoglycans (GAGs) (15 to $30 \%$ of dry weight) [5]. This ECM composition con- fers cartilage functional viscoelastic properties able to sustain the specific compressive, tensile and frictional properties of the joint biomechanics [6]. Actually, the articular surface regeneration still remains a challenge because no long-term satisfactory results have been obtained so far with any of the available techniques used to treat knee lesions [7,8]. The low capacity of regeneration of the tissue is mainly due to its avascular and alymphatic nature [9].

We aim to present in this review different technological strategies to improve cartilage repair based on the clinical outcomes of the current treatment techniques. The objective of this review is to highlight the current concepts on biomaterials, biomechanics, tissue engineering and the actual vision for improving the surgical techniques.

\section{Current cartilage repair techniques}

There are two types of articular cartilage lesions that can be identified: degenerative arthritis, also called osteoarthritis (OA), which is a disease initiated by the loss of proteoglycans from the extracellular matrix and a disruption of the collagenous network therein [11]; and traumatic lesions, which are referred to as an articular cartilage injury or chondral injury (Table 1).
Philippe Abdel-Sayed' \& Dominique P Pioletti ${ }^{*}, 1$ 'Laboratory of Biomechanical Orthopedics, Institute of Bioengineering, École Polytechnique Fédérale de Lausanne (EPFL), Station 19, 1015 Lausanne, Switzerland

*Author for correspondence: Tel.: +41216938341

Fax: +41216938660

dominique.pioletti@epfl.ch
Future
Medicine 


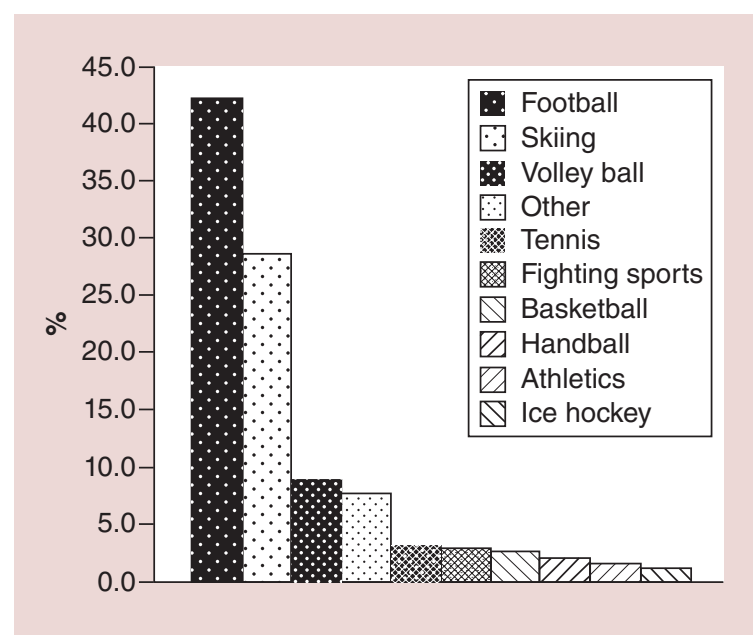

Figure 1. Percentage of knee injury caused by sport activities.

Reproduced with permission from [1].

For color figures, please see online at www.

futuremedicine.com/doi/full/10.2217/NNM.15.119

In case of a traumatic lesion, clinicians grade the severity and complexity of articular cartilage defect based on the depth of the injury [12,13], and as classified by the International Cartilage Repair Society (ICRS; www.cartilage.org/). Grade I is very mild with softening; Grade II includes fissuring or crater depth less than half the full thickness; Grade III is a deep defect that is through most of the thickness of the cartilage; and the most severe, Grade IV is a full thickness defects with exposed bone. Higher-grade lesions (III or IV) can have major negative impact on a person's mobility and life quality. Usually with time, a traumatic lesion leads to OA, though the precise pathophysiology is not yet fully understood $[14,15]$.
There are currently three surgical techniques for the repair of articular cartilage (Figure 3). The first surgical technique is commonly called microfracture (MF). This method was initially developed by Priddie in 1959 and it implies the access to the bone marrow spaces by drilling, which promotes blood clot formation [16]. Then the evolution to microfracturing was introduced by Steadman et al. in 1994 [17]. This procedure is also called marrow stimulation, as access to bone marrow is given to allow the mesenchymal stem cells (MSCs) to migrate to repair the defect. The second surgical technique is the autologous chondrocytes implantation (ACI), which was tried for the first time by Brittberg et al. in 1994 [18]. As indicated by its name, ACI implies a subsequent chondrocyte reinjection after biopsy of a nonload-bearing area of cartilage and ex vivo cell expansion. The third surgical technique is mosaicplasty or osteochondral autograft transfer, which involves the surgical transfer of mature autologous tissue from nonloading-bearing region to a cartilage defect $[19,20]$. This procedure usually concerns cases where subchondral bone is also affected. Likewise, allografts are also used in clinics for osteochondral defects [21].

The main limitation of the MF and $\mathrm{ACI}$ is that the newly formed tissue lacks the structural organization of collagen network and other ECM components, specially in patients over 50 years old, probably because either the MSCs or autologous chondrocytes suffer an age-related loss in their potential to proliferate and differentiate $[23,24]$. Consequently, the neoformed tissue is fibrocartilaginous having inferior quality compared with native tissue and is thus disposed to failure [6]. Nevertheless, MF or ACI techniques allow to close the

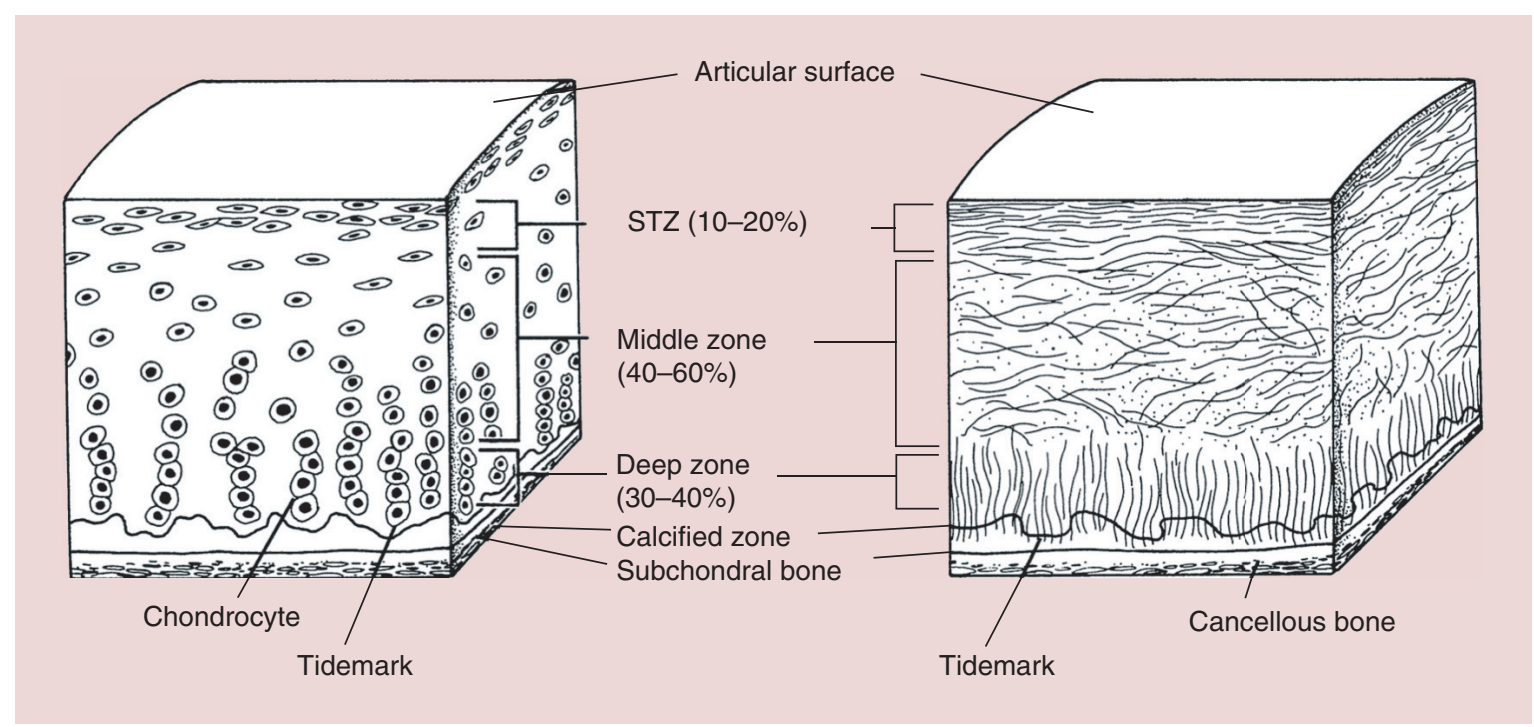

Figure 2. Illustration of articular cartilage showing the distribution and morphology of chondrocytes in the different zones of cartilage, as well as the organization of collagen fibers.

Reproduced with permission from [10]. 
Table 1. Classification of chondral lesions according to the International Cartilage Repair Society system.

\begin{tabular}{|c|c|c|}
\hline Cartilage status & Grade & Description \\
\hline Normal & 0 & Healthy cartilage \\
\hline \multirow[t]{2}{*}{ Almost normal } & $1 a$ & Superficial lesions/softening \\
\hline & $1 b$ & As in 1a and/or superficial cracks or fissures \\
\hline Abnormal & 2 & Extent $<50 \%$ of thickness \\
\hline \multirow[t]{4}{*}{ Severe lesion } & 3a & Extent $>50 \%$ \\
\hline & $3 b$ & Down to the calcified layer \\
\hline & $3 c$ & Down to the surface of the subchondral bone (without penetration) \\
\hline & $3 d$ & Includes budging of the cartilage around the lesion \\
\hline \multirow[t]{2}{*}{ Very severe lesion } & $4 a$ & $\begin{array}{l}\text { Penetration of the subchondral bone but not across the entire diameter of } \\
\text { the defect }\end{array}$ \\
\hline & $4 b$ & Penetration across the full diameter of the defect \\
\hline
\end{tabular}

lesion, to give congruency to the tissue and to reduce the pain, but it is not clear yet if it can reduce the risk of OA development [25].

Lately, several systematic reviews have been published on the comparison of ACI with the two other surgical techniques [26-30]. These reviews could not conclude on the superiority of ACI over MF and osteochondral autograft transfer. Nevertheless, Harris et al. have highlighted that in defects larger than $4 \mathrm{~cm}^{2}$ better outcomes can be expected with ACI, suggesting a treatment depending on the size and severity of the defect (Figure 4). Over 5 years follow-up, no matter which surgical technique has been used, the clinical result is the same and no significant difference remains in the outcomes that is dependent to the size of the defect. In four randomized studies, it has been shown that age is also a parameter that most influenced the cartilage repair, as young patients under the age of 30 years appear to have a better healing independently of the surgery technique compared with patients over the age of 30 years [31].

It has been shown that MF would have a deleterious impact on posterior ACI intervention [32], suggesting thus that it is important to find from the beginning the most appropriate surgical technique to treat cartilage defects.

\section{Clinical products for cartilage repair Cell-based products}

The ACI initial technique, where a periosteal flap is used to maintain the transplanted chondrocytes, is the only technique that is US FDA-approved [33]. While it has shown favorable results with $73.5 \%$ success at mean 12.8 years post surgery [34], remain the issue of $30 \%$ periosteum hypertrophy and a limitation to lesions small in size (average defect size $5.2 \mathrm{~cm}^{2}$ ). This postoperative complication led to the development of mem- branes as substitutes to the periosteal flaps. This technology evolved into a second-generation ACI also called matrix assisted chondrocytes implantation (MACI) procedure. The advantages of using a matrix instead of a periosteum flap are that it mimics in vivo conditions, avoids the periosteum preparation and allows the migration of cells into the matrix, as well as it allows the treatment of larger lesions with less transplant hypertrophy [35]. The different products offered by companies and used in clinics are reported in Table 2.

The main disadvantages of a cell-based approach are that first the harvesting step remains in the case of an autologous implantation, and second the cell culture is time consuming, very expensive and induces cell dedifferentiation [36]. Also, a clear age-dependency on chondrocytes activity has been observed [37] producing then an inherent variability in the treatment outcome. Alternatively, allogeneic cells such as MSCs can be used, but the utility of those latter remains limited due to cells stability and hypertrophy issues (Table 3).

No clinical difference between an ACI or MACI techniques has been shown yet [38], but as multiple matrices were considered in the study it was difficult to compare the results.

\section{Scaffolds}

In order to circumvent the limitations of cell-based procedures, several companies offer to use acellular scaffolds to treat the cartilage defects (Table 4). The idea is to promote the activity of the endogenous progenitor cells by combining those scaffolds with original microfracture technique [39]. Thus, cells migrate through the scaffold, which structurally stabilize the clot to initiate a more robust repair response when compared with MF alone [40]. This process is commonly called autologous matrix-induced chondrogenesis (AMIC). The advan- 


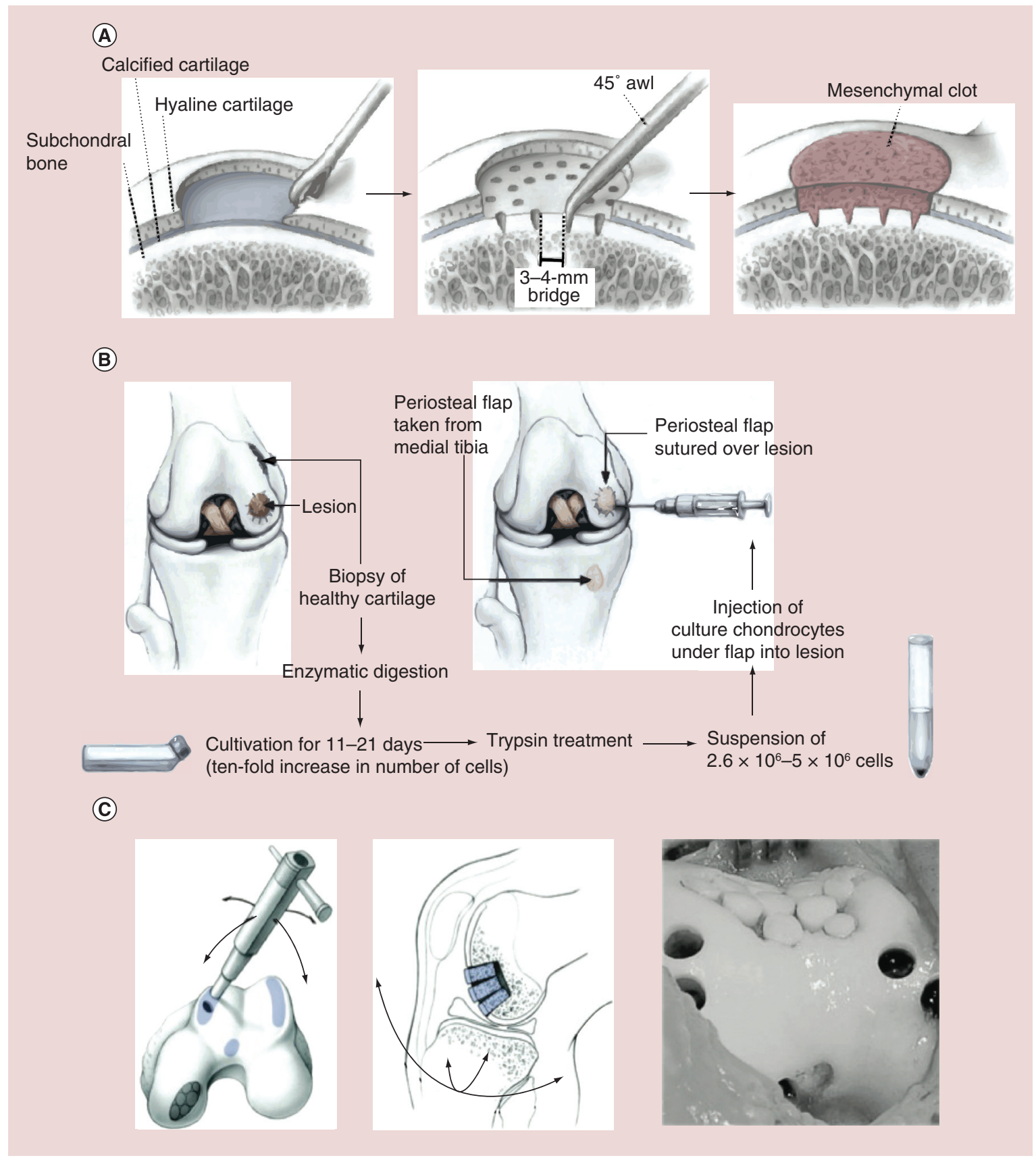

Figure 3. Surgical techniques to treat cartilage. (A) Cartilage repair with the microfracture technique involving several steps that include the debridement to a stable cartilage margin, the careful removal of the calcified cartilage layer and the homogeneous placement of microfracture penetrations within the cartilage defect, with resultant complete defect fill by a well-anchored mesenchymal clot. Reproduced with permission from [22]. (B) Diagram of autologous chondrocytes implantation in the right condyle. Reproduced with permission from [18]. (C) Osteochondral autograft transfer. On the left panel, blue-shaded regions that are recommended as graft donor sites on the femoral articular cartilage. On the middle panel, illustration of the range of motion of the joint after grafting that is tested to insure proper fixation and congruent resurfacing on the grafts. In the right panel, photo of a mosaicplasty performed on the femoral trochlea. Reproduced with permission from [20].

tage of such solid scaffolds or matrices is that they have adequate mechanical properties compared with other systems such as hydrogels, and thus are able to support the physiological load present in the knee. Moreover, the solid scaffold will also be able to transmit the load to the subchondral bone.

The disadvantage of an AMIC approach is that most scaffolds promote cell spreading, which encourages 
fibrous matrix production [41]. While it is recognized that AMIC may not produce tissue that is identical to that of native cartilage, however the neoformed tissue may prevent further deterioration, resulting in clinical improvements for the patient. An extensive review on scaffold-based clinical studies repair for cartilage can be found on the following reference [42].

\section{Hydrogels}

As an alternative to solid scaffolds, diverse hydrogels (Table 5) are now investigated for AMIC approaches [43]. They consist of crosslinked hydrophilic polymer networks having the attractive feature of being minimal-invasively injected as a solution and capable to polymerize in situ. Crosslinking methods include light irradiation, temperature modulation and $\mathrm{pH}$ alteration [33]. Hydrogels used for chondrogenesis can be naturally-derived such as agarose [44,45], collagen $[46,47]$, fibrin [48,49], alginate [50-52] and hyaluronan [53]; or derive from synthetic polymers such as polyethylene glycols hydrogels [54,55]. Some studies have shown that less crosslinked (softer) hydrogels produce dynamic loading that might favor MSC chondrogenesis [56,57].

In comparison to solid scaffolds, hydrogels allow cells to have a more round morphology, characteristic of the chondrogenic phenotype, which reduces the formation of fibrous tissues [58]. Nevertheless, hydrogels have limited mechanical properties, and then more prone to failure, which is a main disadvantage as articular cartilage is subject to high mechanical loads. Also, these types of material still have deficiency in their ability to integrate with the surrounding tissues.

Depending on the chosen surgical technique, it would be judicious to use one or the other material. Hence, solid scaffolds would be recommended for a MACI approach while a hydrogel would be more favorable for an AMIC approach, since usually MF are recommended for small defects. In this latter situation, hydrogels have less chance to fail upon implantation because of their weak mechanical properties.

\section{Improvement strategies}

As already mentioned, it has been shown that ACI has favorable results with $73.5 \%$ success at mean 12.8 years post surgery [34]. However ACI cannot be a universal gold standard treatment as the remaining $26 \%$ of the patients have shown worse final outcome, especially in cases where patients had bipolar lesions. Furthermore, the success of the ACI interventions was established on clinical scores based on questionnaires sent to 341 patients, assessing the pain relief but not the quality of the newly formed cartilage, and the study did not have any preoperative values for any of the patients. Indeed, researchers and surgeons do not have the same focus, since the first looks for a symptom relief while the second aims to recreate preinjury joint tissue, required for a long-term healing. Furthermore, the use of biomaterials in MACI and AMIC interventions gives good clinical results but does not necessarily improve the quality of the neoformed cartilage. In this section, we present some research directions and advances for inducing joints to have the biological capacity of longterm healing, and thus further improve the outcome of the currents surgical treatments.

\section{Evolution of biomaterials platforms}

Functionalization of the implanted biomaterials As seen, several biomaterial platforms have been tested for cartilage repair, either hydrogels or solid scaffolds. A first approach for improving cartilage repair is to improve the integration of the biomaterials used. Indeed, the use of sutures to fix the implanted matrix may destroy the adjacent cartilage, which is not optimal for the cartilage regeneration. Equally, current tissue adhesive, such as cyanoacrylates and fibrin glue, have poor biocompatibility properties and insufficient bonding strength.

In the laboratory stage of development, hydrogels are being modified to include adhesive properties for an increased integration in the tissue [58-60]. Thus, for a better adhesion to the host cartilage, Wang et $a l$. have functionalized chondroitin sulfate polysac-

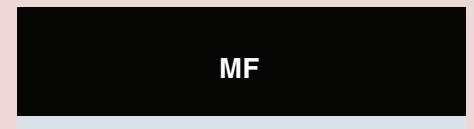

- Cartilage defect grade III-IV

- Subchondral bone intact

- Defect size: $1-2 \mathrm{~cm}^{2}$

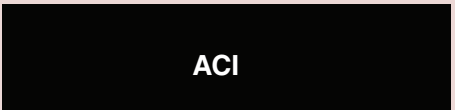

- Cartilage defect grade III-IV

- Subchondral bone intact

- Defect size: $>2 \mathrm{~cm}^{2}$

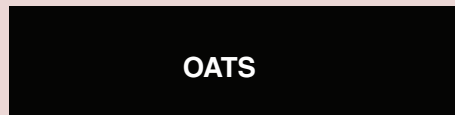

- Osteochondral defect

Figure 4. Choice of the surgical treatment depending of the defect size, as recommended by Bekkers et al. in their systemic review [31]. 
Table 2. Cell-based product commercially available and used in clinics.

\begin{tabular}{|c|c|c|}
\hline Product name & Company & Description \\
\hline $\mathrm{MACl}$ & Genzyme_sanofi & Bilayer collagen I/III matrix \\
\hline CAIS & DePuy Mitek & $35 \%$ polycaprolactone, $65 \%$ polyglycolic acid \\
\hline $\mathrm{ACl}$ & Orthocell & Autologous chondrocytes \\
\hline INSTRUCT & CellCoTec & Autologous chondrocytes with an integrated kit \\
\hline Carticel & Genzyme & Periosteal flap \\
\hline DeNovo ET & ISTO Technologies & Juvenile cartilage implant \\
\hline Regenexx procedures & Centeno-Schultz Clinic & Adult stem cells and blood platelet treatment \\
\hline RepliCart & Mesoblast & Adult stem cells \\
\hline OrthoCyte & Biotime & Human embryonic progenitor cell lines \\
\hline ChondroCelect & TiGenix NV & Autologous chondrocytes \\
\hline NeoCart & Histogenics & $\begin{array}{l}\text { Autologous chondrocytes in collagen I scaffold, for } \\
\text { forming a cartilage before implantation }\end{array}$ \\
\hline Chondron $^{\mathrm{TM}}$ & RMS Regrow $^{\circledast}$ Lab $^{2}$ & Gel-type autologous chondrocytes \\
\hline Bioseed C & BioTissue AG & Autologous chondrocytes grafts \\
\hline Hyalograft-C & Anika Therapeutics & Autologous chondrocytes grafts \\
\hline Biocart II & Prochon Biotech & Fibrin-hyaluronan \\
\hline
\end{tabular}

charides with methacrylate and aldehyde groups to covalently link the cartilage proteins with the polyethylene glycols-based hydrogel they developed [58]. They have tested their material in chondral defects $(3.2 \mathrm{~mm}$ diameter) in the femoropatellar groove of New Zealand white rabbits, and they have shown that with their multifunctional approach they can induce cartilage repair with a mechanical stability. Similarly, solid scaffolds made of poly(vinyl alcohol) were functionalized using a sequential process resulting in reactive carbonate groups on their surface, which can covalently bond with any amino group of the adjacent cartilage and thus increase interfacial strength by a factor of three [61].

Another strategy to enhance lateral integration to cartilage is to include antiapoptosis agents to relieve cell death at the defect edge [62]. In this case, the number of viable cells at the defect edge prevents matrix loss, and implies significant cartilage-cartilage integration. This approach has been tested in vitro with bovine cartilage discs where the inner core was cut but left in situ to create disc-ring composites and cultured up to 6 weeks with/without necrosis inhibitors [62].

Alternative strategy to improve cartilage integration and interfacial strength is to use matrix-degrading enzymes to decrease ECM antiadhesive properties [63]. The treatment with hyaluronidase and collagenase exposes the cells at higher density at the wound edges, and then more prone to deposit ECM resulting to an enhanced bonding with grafts and thus better integration [64]. However, so far this technique still remains at the level of basic research and to our knowledge did not have any clinical follow-up.

Improvements of cartilage grafts with biomechanics

An alternative approach to regenerate cartilage, especially for larger defects, is to culture cartilage grafts in bioreactor systems for an ex vivo growth and maturation of the grafts before implantation in patients [65]. A method to enhance the mechanical properties and maturation of grafts is to apply a mechanical stimulation to the developing tissue before the surgical application [66]. Indeed, it has been shown that uniaxial compression can favor chondrogenesis by upregulating collagen type II and aggrecan expression [67-72]. Dynamic compression increases likewise glycosaminoglycans deposition [73] and improves the compressive modulus of cartilage grafts [74]. The motivation of using such compressive loading comes from the fact that cartilage deformation up to $15 \%$ occurs during direct contact between joint surfaces during normal daily movements, such as walking [75]. Most of the studies relating a dynamic compression used frequencies in the range of 0.01 to $1 \mathrm{~Hz}$ with strains of 10,15 or $20 \%$ [76]. A recent study has shown that frequency and amplitude of stimulation can alter the chondrogenic response of human bone marrow mesenchymal stem cells with maximum expression of collagen type 2 and aggrecan at the highest frequency of $1 \mathrm{~Hz}$ and maximal strain amplitude of $20 \%$ [77]. Nevertheless, particular frequency and amplitude of stimulation may imply a cell response in a specific scaffold that 
would be different in another one, because the mechanotransduction in engineered cartilage may vary substantially between different biomaterials platforms [78] as they do not have the same cell-matrix interaction [47]. Thus, it has recently been proposed that energy dissipation due to a compressive loading might be considered as an overarching variable for optimizing the mechanical stimulation for an enhanced chondrogenesis, as the dissipation encompasses all of the transient fluid-and solid-related physical phenomena occurring subsequent to a dynamic mechanical stimulation [79]. In particular, it has been shown that energy dissipation occurs in cartilage tissue and in biomaterials as they have viscoelastic properties [80], and this dissipation is produced as heat, which in turn increases temperature in cartilage tissue [81,82]. This temperature increase subsequent to a mechanical stimulation has a beneficial effect on chondrogenic expression [83], implying thus the dissipation as a thermo-mechanical variable to consider for the optimization of bioreactor systems. However, no studies have been performed to assess the beneficial effect of a mechanical stimulation compared with improved biomaterials.

\section{Drug delivery systems}

Another alternative technique to improve cartilage repair is to increase the regenerative potential of the biomaterial platforms. Hence, efforts are implemented in research laboratories to modify those biomaterial platforms to incorporate growth factors and other molecules so as to enhance the regeneration process through increased recruitment and differentiation of endogenous progenitor cells $[84,85]$. It has been shown that TGF- $\beta 3$ can be combined with a porous collagen-scaffold to attract stem cells through chemotaxis and to resurface an entire joint in a rabbit [85]. In their study, Lee et al. have shown that TGF- $\beta 3$ released from the scaffold recruited approximately 130\% more cells in the regenerated cartilage than did spontaneous cell migration without TGF- $\beta 3$, suggesting that joint resurfacing does not require cell delivery. Also, hydrogels are especially appropriate for such modifications as they are easily tunable for adding bioactive molecules. So a self-assembling system of amphiphile molecules designed to form nanofibers and having binding epitopes to TGF- $\beta 1$ has been developed [86]. The slow release of the growth factor promoted the regeneration of cartilage. Similarly, such self-assembly structures were engineered in a manner to attenuate local inflammation and therefore temper further cartilage degeneration [87].

A composite hydrogel has been developed to mechanically control the release of growth factors in cartilage in order to simultaneously couple the drug

\section{Table 3. Diverse cell sources used for cartilage repair.}

\begin{tabular}{|c|c|c|}
\hline Cell type & Advantages & Pitfalls \\
\hline \multirow[t]{4}{*}{ Autologous chondrocytes } & Native phenotype & Small initial cell number \\
\hline & $\begin{array}{l}\text { Minimal risk of immunological } \\
\text { problem }\end{array}$ & Dedifferentiation on expansion \\
\hline & & Morbidity on the donor site \\
\hline & & $\begin{array}{l}\text { Double surgery for harvesting and } \\
\text { implanting the cells }\end{array}$ \\
\hline \multirow[t]{2}{*}{ Allogeneic chondrocytes } & Larger cell number & Limited donor availability \\
\hline & Off-the-shelf solution & Risk of disease transmission \\
\hline \multirow{3}{*}{$\begin{array}{l}\text { Adult mesenchymal stem } \\
\text { cells }\end{array}$} & Potential to produce large numbers & Potential for hypertrophy \\
\hline & Various harvest sites & Heterogeneous population of cells \\
\hline & $\begin{array}{l}\text { Additional paracrine signaling } \\
\text { potential }\end{array}$ & $\begin{array}{l}\text { Stable and reproducible differentiation } \\
\text { still problematic }\end{array}$ \\
\hline \multirow[t]{2}{*}{$\begin{array}{l}\text { Induced pluripotent stem } \\
\text { cells }\end{array}$} & Large source of patient-specific cells & $\begin{array}{l}\text { Stable and reproducible differentiation } \\
\text { still problematic }\end{array}$ \\
\hline & Multiple cell types can be produced & Potential for teratoma \\
\hline \multirow[t]{3}{*}{ Embryonic stem cells } & Off-the-shelf solution & $\begin{array}{l}\text { Stable and reproducible differentiation } \\
\text { still problematic }\end{array}$ \\
\hline & Multiple cell types can be produced & Potential for teratoma \\
\hline & & Ethical considerations \\
\hline
\end{tabular}




\begin{tabular}{|c|c|c|}
\hline Product name & Company & Description \\
\hline Agili-C $\mathrm{C}^{\mathrm{M}}$ & CartiHeal Ltd & Modified aragonite and hyaluronic acid \\
\hline CaReS & Arthro Kinetics & Collagen type I matrix (with or without cells) \\
\hline Chondro-Gide & Geistlich & Bilayer collagen I/III matrix \\
\hline Novocart ${ }^{\circledR}$ Basic & TETEC AG & Biphasic 3D collagenous matrix \\
\hline Chondrotissue & BioTissue AG & PGLA fleece with hyaluronic acid \\
\hline Hyalofast & Anika Therapeutics & A benzyl ester of hyaluronic acid \\
\hline TruFit & Smith \& Nephew & Calcium sulphate/PLLA composite \\
\hline Maix & Matricel & Collagen \\
\hline MaioRegen & JRI Orthopedics Ltd & $\begin{array}{l}\text { Deantigenated type I equine collagen with a lower layer mostly } \\
\text { composed of magnesium-enriched hydroxyapatite }\end{array}$ \\
\hline
\end{tabular}

delivery with cell receptors activation, which is essential for an enhancement of the tissue regeneration [88]. Indeed, mechanical loading has been shown to activate cell receptors to growth factors involved in the regeneration of cartilage [89-91], therefore a temporally adapted delivery induces maximum potency of the drug.

Nonetheless, it has to be mentioned that the addition of growth factors could have deleterious effects on cartilage when exceeding a certain amount, such as marked hyperplasia of the synovium and chondroosteophyte formation [92]. Thus the use of growth factors still requires several tests to determine the best concentration inducing only positive effect. Moreover, the addition of any biological components, such as growth factors, might be a barrier in the translation into clinics as it will involve greater examination than would be for the deliver materials alone. This will considerably complicate the regulatory process. Indeed, the regulatory agencies would consider many of the functionalized biomaterials as a combination product, where each component may need to be tested separately and in combination for its safety. Hence, the time and costs associated with the development and the translation of those new platforms should be well estimated according to the benefits of adding soluble factors.

\section{Scaffold-free approaches}

In order to overcome the challenges associated with scaffold use, scaffold-free techniques promoting the formation of biomechanically functional neocartilage without using scaffolds have been proposed [5,93-94]. Initially scaffold-free techniques were used to form small spherical aggregates of cells, for instance, by centrifugation, to study chondrogenesis. Indeed, with this process a reminiscence of mesenchymal condensation during cartilage development occurs involving cell-cell and cell-matrix interactions, which results in collagen VI deposition around chondrocytes and collagen II throughout the micro-tissue. Moreover, as this technique allows the cells to take a rounded morphology favorable for a chondrogenic phenotype [95], recent research has expanded it to the generation of cartilage constructs [96]. Ofek et al. have developed a technique, in which chondrocytes are presented only to nonadherent surfaces to allow cells' self-assembly driven by free energy minimization. The neoformed tissue shows gross morphological, histological, biochemical and biomechanical similarities to native cartilage after 4 weeks [97]. Alternatively, cells can be expanded in monolayer up to a high confluence, in order to produce sufficient ECM to form a cohesive sheet that is lifted from the substrate as a whole [98]. Released cell sheets can then be rolled, layered or draped over molds [99].

Table 5. Hydrogels commercially available and used in clinics for autologous matrix-induced chondrogenesis procedures.

\begin{tabular}{|lll|}
\hline Product name & Company & Description \\
\hline CartiPatch & TBF Tissue Engineering & Agarose-alginate hydrogel \\
\hline ChonDux & Biomet & Photopolymerized PEG \\
GelrinC & Regentis & PEG/fibrin \\
\hline BST-CarGel & Piramal Life Sciences & Chitosan-based hydrogel \\
\hline
\end{tabular}


Direct culture of bone marrow stromal cells on porous polyphosphate substrates allowed developing scaffold-free osteochondral constructs having a biphasic structure with a calcified zone in cartilage $[100,101]$. However, in a scaffold-free method it is important to keep the neoformed tissue long enough in culture so that it is mature to sustain the mechanical loading when implanted.

Higher ECM content and mechanical properties have been generated in cartilaginous tissues without scaffolds when compared with scaffoldbased approach [102,103]. Currently, scaffold-free technologies [37,104] are undergoing clinical trials [6].

To form a neocartilage tissue, a scaffold-free method necessitates a large number of cells compared with a scaffold-based approach as the exogenous biomaterial is missing. Autologous cells remain the best option for a clinical translation, but they show limitations with the number of primary cells available and morbidity of the donor site [99]. Therefore further investigations are dedicated to find alternative cells source. Thus, Darwiche et al. propose epiphyseal chondroprogenitors as a stable cell source for cartilage cell therapy [105]. Indeed, extraordinary ability for self-repair has been shown by fetal cartilage cells [106], as well as an immune-modulatory activity $[107,108]$.

Because of the immunological profile and their prededicated differentiation phenotype, epiphyseal chondroprogenitors would show superior stability in withstanding environmental variability over the quasiquiescent adult chondrocytes, and present over stem cells an interesting potential for allogeneic cell source in tissue-engineering applications.

Alternative strategy to improve cartilage tissue engineering without altering the biomaterials would also be to use genetically modified cells. Indeed, it has been shown that transfected chondrocytes induced to express TGF- $\beta 1$ enhance cartilage formation [109]. Nevertheless, no study has been performed to compare the efficacy between a scaffold-free approach and functionalized scaffolds. But here again, the hurdle of the regulatory process has to be considered in the development of gene therapies.

\section{Conclusion}

Research advances in biomaterials with promising in vivo results open new perspectives in the development of cartilage repair approaches, but the advantage of these new strategies compared with established cartilage repair techniques is not yet established in clinics. Likewise, the potential of using scaffold-free approaches by harnessing the potential of progenitor cells, or other allogeneic cells source, to create organized hyaline-like repair tissue in situ remains hypothesis to verify. Would it be possible one day that scientists could harness biology and recapitulate or engineer the simplest tissues of the body such as cartilage? Longterm follow-up and more comparative systematic trials are required to establish the best method for cartilage regeneration. Also, in tissue engineering the regulatory process is pivotal, and should be one of the first aspects considered in the development of new strategies in general and in biomaterial platforms in particular.

\section{Future perspective}

The constantly increasing number of publications and products development for cartilage repair reflects the interest and technological advances in the field. However, cartilage repair still remains deficient to some extent and its market still is to be conquered. Advances

\section{Executive summary}

- Despite diverse approaches, nowadays there is no treatment that is able to restore hyaline-like cartilage with native tissue characteristics.

- The current surgical techniques for the repair of articular cartilage are microfracture, autologous chondrocytes implantation and mosaicplasty.

- Randomized clinical trials have shown that none of the surgical technique is superior to the others over a 5 years follow-up.

- Clinical products used in cartilage repair are cell-based matrices, solid scaffolds and hydrogels.

- Strategies to improve cartilage repair are to develop biomaterials such as to functionalize the implanted biomaterial platforms to have a better integration in the tissue; to enhance the tissue formation and matrix organization in the cartilage grafts thanks to mechanical stimulation prior to implantation; to locally deliver growth factors or drugs by the means of the implanted materials and scaffold-free approaches, such as allogeneic cell sources and gene therapies.

- Research advances in biomaterials with promising in vivo results open new perspectives in the development of cartilage repair approaches, but the advantage of these new strategies compared with established cartilage repair techniques is not yet established in clinics.

- The regulatory process is pivotal and should be one of the first aspects considered in the development of a new cartilage repair strategy in general and in biomaterial platforms in particular. 
in basic research for cartilage repair should lead to improved clinical therapies, however their success will be depending on their capability to simplifying the surgical procedures and to enhance the tissue regeneration. Finally, only the well designed prospective clinical studies will dictate the survival of a novel therapy by validating and comparing its efficacy to existing therapies and will allow overcoming the regulation process.

\section{References}

Papers of special note have been highlighted as:

- of interest; $\bullet$ of considerable interest

1 Widuchowski W, Widuchowski J, Trzaska T. Articular cartilage defects: study of 25,124 knee arthroscopies. Knee 14(3), 177-182 (2007).

2 Aroen A, Loken S, Heir $S$ et al. Articular cartilage lesions in 993 consecutive knee arthroscopies. Am. J. Sport Med. 32(1), 211-215 (2004).

3 Curl WW, Krome J, Gordon ES, Rushing J, Smith BP, Poehling GG. Cartilage injuries: a review of 31,516 knee arthroscopies. Arthroscopy 13(4), 456-460 (1997).

4 Walczak BE, Mcculloch PC, Kang RW, Zelazny A, Tedeschi F, Cole BJ. Abnormal findings on knee magnetic resonance imaging in asymptomatic nba players. J. Knee Surg. 21(1), 27-33 (2008).

5 Athanasiou KA, Darling EM, Hu JC. Articular cartilage tissue engineering. Synthesis Lectures on Tissue Engineering 1(1), 1-182 (2009).

6 Huey DJ, Hu JC, Athanasiou KA. Unlike bone, cartilage regeneration remains elusive. Science 338(6109), 917-921 (2012).

7 Mollon B, Kandel R, Chahal J, Theodoropoulos J. The clinical status of cartilage tissue regeneration in humans. Osteoarthritis Cartilage 21(12), 1824-1833 (2013).

8 Johnstone B, Alini M, Cucchiarini M et al. Tissue engineering for articular cartilage repair - the state of the art. Eur. Cells Mater. 25, 248-267 (2013).

9 Oldershaw RA. Cell sources for the regeneration of articular cartilage: the past, the horizon and the future. Int. J. Exp. Pathol. 93(6), 389-400 (2012).

10 Buckwalter JA, Mow VC, Ratcliffe A. Restoration of injured or degenerated articular cartilage. J. Am. Acad. Orthop. Surg. 2(4), 192-201 (1994).

11 Wieland HA, Michaelis M, Kirschbaum BJ, Rudolphi KA. Osteoarthritis - an untreadisease? Nat. Rev. Drug Discov. 4(4), 331-344 (2005).

12 Brittberg M, Winalski CS. Evaluation of cartilage injuries and repair. J. Bone Joint Surg. Am. 85 (A Suppl. 2), 58-69 (2003).

13 Outerbridge RE. The etiology of chondromalacia of the patella. J. Bone Joint Surg. Br. 43(3), 613-613 (1961).

14 Chrisman OD, Ladenbauerbellis IM, Panjabi M. The relationship of mechanical trauma and the early biochemical reactions of osteoarthritic cartilage. Clin. Orthop. Relat. R. (161), 275-284 (1981).
Financial \& competing interests disclosure

The authors have no relevant affiliations or financial involvement with any organization or entity with a financial interest in or financial conflict with the subject matter or materials discussed in the manuscript. This includes employment, consultancies, honoraria, stock ownership or options, expert testimony, grants or patents received or pending, or royalties.

No writing assistance was utilized in the production of this manuscript.

15 Olson SA, Guilak T. From articular fracture to posttraumatic arthritis: a black box that needs to be opened. J. Orthop. Trauma 20(10), 661-662 (2006).

16 Insall JN. Intra-articular surgery for degenerative arthritis of the knee. A report of the work of the late k. H. Pridie. J. Bone Joint Surg. Br. 49 (2), 211-228 (1967).

17 Steadman JR, Rodkey WG, Rodrigo JJ. Microfracture: surgical technique and rehabilitation to treat chondral defects. Clin. Orthop. Relat. R. (391), S362-S369 (2001).

- First article that describes the microfracture technique.

18 Brittberg M, Lindahl A, Nilsson A, Ohlsson C, Isaksson O, Peterson L. Treatment of deep cartilage defects in the knee with autologous chondrocyte transplantation. N. Engl. J. Med. 331(14), 889-895 (1994).

- First article that describes the autologous chondrocyte implantation technique.

19 Mcdermott AG, Langer F, Pritzker KP, Gross AE. Fresh small-fragment osteochondral allografts. Long-term followup study on first 100 cases. Clin. Orthop. Relat. R. (197), 96-102 (1985).

20 Hangody L, Fules P. Autologous osteochondral mosaicplasty for the treatment of full-thickness defects of weight-bearing joints - ten years of experimental and clinical experience. J. Bone Joint Surg. Am. 85A, 25-32 (2003).

21 Capeci CM, Turchiano M, Strauss EJ, Youm T. Osteochondral allografts: applications in treating articular cartilage defects in the knee. Bull. Hosp. Jt Dis. 71(1), 60-67 (2013).

22 Mithoefer K, Mcadams T, Williams RJ, Kreuz PC, Mandelbaum BR. Clinical efficacy of the microfracture technique for articular cartilage repair in the knee an evidence-based systematic analysis. Am. J. Sport Med. 37(10), 2053-2063 (2009).

23 Zheng H, Martin JA, Duwayri Y, Falcon G, Buckwalter JA. Impact of aging on rat bone marrow-derived stem cell chondrogenesis. J. Gerontol. A Biol. Sci. Med. Sci. 62(2), 136-148 (2007).

24 Hunziker EB. The elusive path to cartilage regeneration. Adv. Mater. 21(32-33), 3419-3424 (2009).

25 Mobasheri A, Kalamegam G, Musumeci G, Batt ME. Chondrocyte and mesenchymal stem cell-based therapies for cartilage repair in osteoarthritis and related orthopaedic conditions. Maturitas 78(3), 188-198 (2014).

26 Harris JD, Siston RA, Brophy RH, Lattermann C, Carey JL, Flanigan DC. Failures, re-operations, and complications after autologous chondrocyte implantation - a systematic review. Osteoarthritis Cartilage 19(7), 779-791 (2011). 
27 Clar C, Cummins E, Mcintyre L et al. Clinical and costeffectiveness of autologous chondrocyte implantation for cartilage defects in knee joints: systematic review and economic evaluation. Health Technol. Assess. 9(47), iii-iv, ix-x, 1-82 (2005).

28 Vasiliadis HS, Wasiak J, Salanti G. Autologous chondrocyte implantation for the treatment of cartilage lesions of the knee: a systematic review of randomized studies. Knee Surg. Sports Traumatol. Arthrosc. 18(12), 1645-1655 (2010).

-. Review assessing and comparing the clinical outcome of the different surgical techniques.

29 Vavken P, Samartzis D. Effectiveness of autologous chondrocyte implantation in cartilage repair of the knee: a systematic review of controlled trials. Osteoarthritis Cartilage 18(6), 857-863 (2010).

30 Harris JD, Siston RA, Pan X, Flanigan DC. Autologous chondrocyte implantation: a systematic review. J. Bone Joint Surg. Am. 92(12), 2220-2233 (2010).

31 Bekkers JE, Inklaar M, Saris DB. Treatment selection in articular cartilage lesions of the knee: a systematic review. Am. J. Sports Med. 37(Suppl. 1), S148-S155 (2009).

32 Moran CJ, Pascual-Garrido C, Chubinskaya S et al. Restoration of articular cartilage. J. Bone Joint Surg. Am. 96A(4), 336-344 (2014).

- Reference describing the negative impact of microfracture on later autologous chondrocyte implantation if required.

33 Dewan AK, Gibson MA, Elisseeff JH, Trice ME. Evolution of autologous chondrocyte repair and comparison to other cartilage repair techniques. Biomed. Res. Int. 2014, 272481 (2014).

34 Peterson L, Vasiliadis HS, Brittberg M, Lindahl A. Autologous chondrocyte implantation: a long-term followup. Am. J. Sports Med. 38(6), 1117-1124 (2010).

35 Steinwachs M, Kreuz PC. Autologous chondrocyte implantation in chondral defects of the knee with a type I/III collagen membrane: a prospective study with a 3 year followup. Arthroscopy 23(4), 381-387 (2007).

36 Schnabel M, Marlovits S, Eckhoff G et al. Dedifferentiationassociated changes in morphology and gene expression in primary human articular chondrocytes in cell culture. Osteoarthritis Cartilage 10(1), 62-70 (2002).

37 Adkisson HD, Martin JA, Amendola RL et al. The potential of human allogeneic juvenile chondrocytes for restoration of articular cartilage. Am. J. Sport Med. 38(7), 1324-1333 (2010).

38 Zeifang F, Oberle D, Nierhoff C, Richter W, Moradi B, Schmitt $\mathrm{H}$. Autologous chondrocyte implantation using the original periosteum-cover technique versus matrix-associated autologous chondrocyte implantation a randomized clinical trial. Am. J. Sport Med. 38(5), 924-933 (2010).

39 Burdick JA, Mauck RL, Gorman JH, Gorman RC. Acellular biomaterials: an evolving alternative to cell-based therapies. Sci. Transl. Med. 5(176), 176ps4 (2013).

40 Sharma B, Fermanian S, Gibson M et al. Human cartilage repair with a photoreactive adhesive-hydrogel composite. Sci. Transl. Med. 5(167), 167ra6 (2013).

41 Breinan HA, Martin SD, Hsu HP, Spector M. Healing of canine articular cartilage defects treated with microfracture, a type-ii collagen matrix, or cultured autologous chondrocytes. J. Orthopaed. Res. 18(5), 781-789 (2000).

42 Filardo G, Kon E, Roffi A, Di Martino A, Marcacci M. Scaffold-based repair for cartilage healing: a systematic review and technical note. Arthroscopy 29(1), 174-186 (2013).

43 Erggelet C, Endres M, Neumann K et al. Formation of cartilage repair tissue in articular cartilage defects pretreated with microfracture and covered with cell-free polymer-based implants. J. Orthop. Res. 27(10), 1353-1360 (2009).

44 Huang CYC, Reuben PM, D'ippolito G, Schiller PC, Cheung HS. Chondrogenesis of human bone marrowderived mesenchymal stem cells in agarose culture. Anat. Rec. Part A 278A(1), 428-436 (2004).

45 Kisiday JD, Kopesky PW, Evans CH, Grodzinsky AJ, Mcilwraith CW, Frisbie DD. Evaluation of adult equine bone marrow- and adipose-derived progenitor cell chondrogenesis in hydrogel cultures. J. Orthopaed. Res. 26(3), 322-331 (2008).

46 Wakitani S, Imoto K, Yamamoto T, Saito M, Murata N, Yoneda M. Human autologous culture expanded bone marrow mesenchymal cell transplantation for repair of cartilage defects in osteoarthritic knees. Osteoarthritis Cartilage 10(3), 199-206 (2002).

47 Connelly JT, Petrie TA, Garcìa AJ, Levenston ME. Fibronectin-and collagen-mimetic ligands regulate bone marrow stromal cell chondrogenesis in three-dimensional hydrogels. Eur. Cells Mater. 22, 168-177 (2011).

48 Lee CR, Grad S, Gorna K, Gogolewski S, Goessl A, Alini M. Fibrin-polyurethane composites for articular cartilage tissue engineering: a preliminary analysis. Tissue Eng. 11(9-10), 1562-1573 (2005).

49 Li Z, Kupcsik L, Yao SJ, Alini M, Stoddart MJ. Chondrogenesis of human bone marrow mesenchymal stem cells in fibrin-polyurethane composites. Tissue Eng. Part A 15(7), 1729-1737 (2009).

50 Campbell JJ, Lee DA, Bader DL. Dynamic compressive strain influences chondrogenic gene expression in human mesenchymal stem cells. Biorheology 43(3-4), 455-470 (2006).

51 Diduch DR, Jordan LCM, Mierisch CM, Balian G. Marrow stromal cells embedded in alginate for repair of osteochondral defects. Arthroscopy 16(6), 571-577 (2000).

52 Connelly JT, Garcì AJ, Levenston ME. Inhibition of in vitro chondrogenesis in rgd-modified three-dimensional alginate gels. Biomaterials 28(6), 1071-1083 (2007).

53 Angele P, Schumann D, Angele $M$ et al. Cyclic, mechanical compression enhances chondrogenesis of mesenchymal progenitor cells in tissue engineering scaffolds. Biorheology 41(3-4), 335-346 (2004).

54 Bryant SJ, Anseth KS. Hydrogel properties influence ecm production by chondrocytes photoencapsulated in poly(ethylene glycol) hydrogels. J. Biomed. Mater. Res. 59(1), 63-72 (2002).

55 Nicodemus GD, Bryant SJ. Cell encapsulation in biodegradable hydrogels for tissue engineering applications. Tissue Eng. Part B Rev. 14(2), 149-165 (2008).

56 Spiller KL, Maher SA, Lowman AM. Hydrogels for the repair of articular cartilage defects. Tissue Eng. Part B Rev. 17(4), 281-299 (2011). 
57 Elisseeff J, Puleo C, Yang F, Sharma B. Advances in skeletal tissue engineering with hydrogels. Orthod. Craniofac. Res. 8(3), 150-161 (2005).

58 Wang DA, Varghese S, Sharma B et al. Multifunctional chondroitin sulphate for cartilage tissue-biomaterial integration. Nat. Mater. 6(5), 385-392 (2007).

- Reference describing the functionalization of hydrogels to improve their adhesive properties in cartilage.

59 Yang SQ, Guo QY, Shores LS et al. Use of a chondroitin sulfate bioadhesive to enhance integration of bioglass particles for repairing critical-size bone defects. J. Biomed. Mater. Res. Part A 103(1), 235-242 (2015).

60 Chae JJ, Mulreany DG, Guo Q et al. Application of a collagen-based membrane and chondroitin sulfate-based hydrogel adhesive for the potential repair of severe ocular surface injuries. Mil. Med. 179(6), 686-694 (2014).

61 Allon AA, Ng KW, Hammoud S et al. Augmenting the articular cartilage-implant interface: functionalizing with a collagen adhesion protein. J. Biomed. Mater. Res. A 100(8), 2168-2175 (2012).

62 Gilbert SJ, Singhrao SK, Khan IM et al. Enhanced tissue integration during cartilage repair in vitro can be achieved by inhibiting chondrocyte death at the wound edge. Tissue Eng. Part A 15(7), 1739-1749 (2009).

63 Bravenboer JV, Der Maur CDI, Bos PK et al. Improved cartilage integration and interfacial strength after enzymatic treatment in a cartilage transplantation model. Arthritis Res. Ther. 6(5), R469-R476 (2004).

64 Bos PK, Degroot J, Budde M, Verhaar JA, Van Osch GJ. Specific enzymatic treatment of bovine and human articular cartilage: implications for integrative cartilage repair. Arthritis Rheum. 46(4), 976-985 (2002).

65 Santoro R, Olivares AL, Brans G et al. Bioreactor based engineering of large-scale human cartilage grafts for joint resurfacing. Biomaterials 31(34), 8946-8952 (2010).

66 Hettrich CM, Crawford D, Rodeo SA. Cartilage repair: third-generation cell-based technologies - basic science, surgical techniques, clinical outcomes. Sports Med. Arthrosc. 16(4), 230-235 (2008).

67 Mauck RL, Byers BA, Yuan X, Tuan RS. Regulation of cartilaginous ecm gene transcription by chondrocytes and mscs in $3 \mathrm{~d}$ culture in response to dynamic loading. Biomech. Model. Mechan. 6(1-2), 113-125 (2007).

68 Li Z, Kupcsik L, Yao SJ, Alini M, Stoddart MJ. Mechanical load modulates chondrogenesis of human mesenchymal stem cells through the tgf-beta pathway. J. Cell Mol. Med. 14(6), 1338-1346 (2010).

69 Mouw JK, Connelly JT, Wilson CG, Michael KE, Levenston ME. Dynamic compression regulates the expression and synthesis of chondrocyte-specific matrix molecules in bone marrow stromal cells. Stem Cells 25(3), 655-663 (2007).

70 Huang AH, Farrell MJ, Mauck RL. Mechanics and mechanobiology of mesenchymal stem cell-based engineered cartilage. J. Biomech. 43(1), 128-136 (2010).

71 Huang CY, Reuben PM, Cheung HS. Temporal expression patterns and corresponding protein inductions of early responsive genes in rabbit bone marrow-derived mesenchymal stem cells under cyclic compressive loading. Stem Cells 23(8), 1113-1121 (2005).

72 Terraciano V, Hwang N, Moroni L et al. Differential response of adult and embryonic mesenchymal progenitor cells to mechanical compression in hydrogels. Stem Cells 25(11), 2730-2738 (2007).

73 Nicodemus GD, Bryant SJ. Mechanical loading regimes affect the anabolic and catabolic activities by chondrocytes encapsulated in peg hydrogels. Osteoarthritis Cartilage 18(1), 126-137 (2010).

74 Appelman TP, Mizrahi J, Elisseeff JH, Seliktar D. The differential effect of scaffold composition and architecture on chondrocyte response to mechanical stimulation. Biomaterials 30(4), 518-525 (2009).

75 Liu F, Kozanek M, Hosseini A et al. In vivo tibiofemoral cartilage deformation during the stance phase of gait. J. Biomech. 43(4), 658-665 (2010).

76 Grodzinsky AJ, Levenston ME, Jin M, Frank EH. Cartilage tissue remodeling in response to mechanical forces. Annu. Rev. Biomed. Eng. 2, 691-713 (2000).

77 Li Z, Yao SJ, Alini M, Stoddart MJ. Chondrogenesis of human bone marrow mesenchymal stem cells in fibrinpolyurethane composites is modulated by frequency and amplitude of dynamic compression and shear stress. Tissue Eng. Part A 16(2), 575-584 (2010).

78 Hunter C, Mouw JK, Levenston ME. Dynamic compression of chondrocyte-seeded fibrin gels: effects on matrix accumulation and mechanical stiffness. Osteoarthritis Cartilage 12(2), 117-130 (2004).

79 Abdel-Sayed P, Darwiche SE, Kettenberger U, Pioletti DP. The role of energy dissipation of polymeric scaffolds in the mechanobiological modulation of chondrogenic expression. Biomaterials 35(6), 1890-1897 (2014).

- Reference describing the importance of mechanical stimulation and the effect of dissipation on chondrogenesis.

80 Shaw MT, Macknight WJ. Introduction To Polymer Viscoelasticity. Wiley, NJ, USA (2005).

81 Abdel-Sayed P, Moghadam MN, Salomir R, Tchernin D, Pioletti DP. Intrinsic viscoelasticity increases temperature in knee cartilage under physiological loading. J. Mech. Behav. Biomed. 30, 123-130 (2014).

82 Moghadam MN, Abdel-Sayed P, Camine VM, Pioletti DP. Impact of synovial fluid flow on temperature regulation in knee cartilage. J. Biomech. 48(2), 370-374 (2015).

83 Abdel-Sayed P, Vogel A, Moghadam MN, Pioletti DP. Cartilage self-heating contributes to chondrogenic expression. Eur. Cells Mater. 26, 171-178 (2013).

84 Fong ELS, Chan CK, Goodman SB. Stem cell homing in musculoskeletal injury. Biomaterials 32(2), 395-409 (2011).

85 Lee CH, Cook JL, Mendelson A, Moioli EK, Yao H, Mao JJ. Regeneration of the articular surface of the rabbit synovial joint by cell homing: a proof of concept study. Lancet 376(9739), 440-448 (2010).

86 Shah RN, Shah NA, Del Rosario Lim MM, Hsieh C, Nuber G, Stupp SI. Supramolecular design of self-assembling nanofibers for cartilage regeneration. Proc. Natl Acad. Sci. USA 107(8), 3293-3298 (2010). 
-. Reference describing supramolecular structure for the delivery of drugs to improve cartilage regeneration.

Whitmire RE, Wilson DS, Singh A, Levenston ME, Murthy N, Garcia AJ. Self-assembling nanoparticles for intra-articular delivery of anti-inflammatory proteins. Biomaterials 33(30), 7665-7675 (2012).

88 Moghadam MN, Kolesov V, Vogel A, Klok HA, Pioletti DP. Controlled release from a mechanically-stimulated thermosensitive self-heating composite hydrogel. Biomaterials 35(1), 450-455 (2014).

Discher DE, Mooney DJ, Zandstra PW. Growth factors, matrices, and forces combine and control stem cells. Science 324(5935), 1673-1677 (2009).

90 Mauck RL, Nicoll SB, Seyhan SL, Ateshian GA, Hung CT. Synergistic action of growth factors and dynamic loading for articular cartilage tissue engineering. Tissue Eng. 9(4), 597-611 (2003).

91 Neu CP, Khalafi A, Komvopoulos K, Schmid TM, Reddi AH. Mechanotransduction of bovine articular cartilage superficial zone protein by transforming growth factor beta signaling. Arthritis Rheum. 56(11), 3706-3714 (2007).

92 Davidson ENB, Vitters EL, Van Den Berg WB, Van Der Kraan PM. TGF beta-induced cartilage repair is maintained but fibrosis is blocked in the presence of smad7. Arthritis Res. Ther. 8(3), R65 (2006).

93 Brenner JM, Ventura NM, Tse MY et al. Implantation of scaffold-free engineered cartilage constructs in a rabbit model for chondral resurfacing. Artif. Organs 38(2), E21-E32 (2014).

94 Shimomura K, Moriguchi Y, Ando W et al. Osteochondral repair using a scaffold-free tissue-engineered construct derived from synovial mesenchymal stem cells and a hydroxyapatite-based artificial bone. Tissue Eng. Part A 20(17-18), 2291-2304 (2014).

95 Imabayashi $\mathrm{H}$, Mori $\mathrm{T}$, Gojo $\mathrm{S}$ et al. Redifferentiation of dedifferentiated chondrocytes and chondrogenesis of human bone marrow stromal cells via chondrosphere formation with expression profiling by large-scale cdna analysis. Exp. Cell Res. 288(1), 35-50 (2003).

96 Bhumiratana S, Eton RE, Oungoulian SR, Wan LQ, Ateshian GA, Vunjak-Novakovic G. Large, stratified, and mechanically functional human cartilage grown in vitro by mesenchymal condensation. Proc. Natl Acad. Sci. USA 111(19), 6940-6945 (2014).

97 Ofek G, Revell CM, Hu JC, Allison DD, Grande-Allen KJ, Athanasiou KA. Matrix development in self-assembly of articular cartilage. PloS ONE 3(7), e2795( 2008).
- Reference describing a scaffold-free approach to have functional-engineered cartilage constructs.

98 Sato M, Yamato M, Hamahashi K, Okano T, Mochida J. Articular cartilage regeneration using cell sheet technology. Anat. Rec. 297(1), 36-43 (2014).

99 Duraine GD, Brown WE, Hu JC, Athanasiou KA. Emergence of scaffold-free approaches for tissue engineering musculoskeletal cartilages. Ann. Biomed. Eng. 43(3), 543-554 (2014).

100 Kandel RA, Grynpas M, Pilliar R et al. Repair of osteochondral defects with biphasic cartilagecalcium polyphosphate constructs in a sheep model. Biomaterials 27(22), 4120-4131 (2006).

101 Allan KS, Pilliar RM, Wang J, Grynpas MD, Kandel RA. Formation of biphasic constructs containing cartilage with a calcified zone interface. Tissue Eng. 13(1), 167-177 (2007).

102 Dehne T, Karlsson C, Ringe J, Sittinger M, Lindahl A. Chondrogenic differentiation potential of osteoarthritic chondrocytes and their possible use in matrix-associated autologous chondrocyte transplantation. Arthritis Res. Ther. 11(5), R133 (2009).

103 Aufderheide AC, Athanasiou KA. Assessment of a bovine coculture, scaffold-free method for growing meniscus-shaped constructs. Tissue Eng. 13(9), 2195-2205 (2007).

104 Schubert T, Anders S, Neumann E et al. Long-term effects of chondrospheres on cartilage lesions in an autologous chondrocyte implantation model as investigated in the scid mouse model. Int. J. Mol. Med. 23(4), 455-460 (2009).

105 Darwiche SE, Scaletta C, Raffoul W, Pioletti DP, Applegate LA. Epiphyseal chondroprogenitors provide a scell source for cartilage cell therapy. Cell Medicine 4, 23-32 (2012).

106 Namba RS, Meuli M, Sullivan KM, Le AX, Adzick NS. Spontaneous repair of superficial defects in articular cartilage in a fetal lamb model. J. Bone Joint Surg. Am. 80 (1), 4-10 (1998).

107 Montjovent MO, Bocelli-Tyndall C, Scaletta C et al. In vitro characterization of immune-related properties of human fetal bone cells for potential tissue engineering applications. Tissue Eng. Part A 15(7), 1523-1532 (2009).

108 Ramelet AA, Hirt-Burri N, Raffoul W et al. Chronic wound healing by fetal cell therapy may be explained by differential gene profiling observed in fetal versus old skin cells. Exp. Gerontol. 44(3), 208-218 (2009).

$109 \mathrm{Ha} \mathrm{CW}$, Noh MJ, Choi KB, Lee KH. Initial Phase I safety of retrovirally transduced human chondrocytes expressing transforming growth factor-beta- 1 in degenerative arthritis patients. Cytotherapy 14(2), 247-256 (2012). 